\title{
EFEK SUMUR RESAPAN TERHADAP PENGURANGAN VOLUME LIMPASAN PERMUKAAN
}

\author{
I WAYAN YASA ${ }^{1)}$, SASMITO SOEKARNO ${ }^{2)}$, I DEWA GEDE JAYA NEGERA ${ }^{3)}$ \\ Jurusan Teknik Sipil, Fakultas Teknik, Universitas Mataram \\ e-mail : Yasaiwayan68@unram.ac.id
}

\begin{abstract}
ABSTRAK
Perubahan tataguna lahan selain berpengaruh pada komponen hidrologi, juga berdampak pada sektor lingkungan yaitu meningkatnya frekuensi terjadinya banjir dan genangan, menurunnya ketersediaan air bawah permukaan dan mengeringnya sumur-sumur masyarakat. Berbagai usaha telah dilakukan dalam upaya mengurangi banjir dan mempertahankan sumber-sumber air bawah permukaan yaitu dengan menerapkan teknologi sumur resapan di setiap pemukiman. Sumur resapan akan dapat berfungsi untuk memasukan kembali air hujan yang jatuh di perkerasan dan dapat mengurangi terjadinya banjir dan genangan.

Penelitian ini dilakukan dengan model empiris yaitu menghubungkan besarnya nilai limpasan yang terjadi setelah tersedianya sumur resapan. Tujuan dari penelitian yaitu mendapatkan besarnya kemampuan dari sumur resapan dalam mengurangi terjadinya banjir di suatu wilayah. Data yang digunakan dalam analysis yaitu data hujan dan data tekstur tanah. Berdasarkan hasil analisis diperoleh dimensi sumur resapan 0,8 m, $1 \mathrm{~m}$ dan 1,2 $\mathrm{m}$ dengan kedalaman $2 \mathrm{~m}$. Kedalaman muka air tanah sebesar 1,94 m, nilai permeabilitas (k) tanah sebesar $0,24 \times 10^{-4} \mathrm{~m} /$ detik.Dari masing-masing diameter sumur resapan tersebut mampu mengurangi terjadinya limpasan berturut-turut yaitu; sumur resapan diameter $0,8 \mathrm{~m}$ dari limpasan sebesar $0,479 \mathrm{~m}^{3} /$ detik dan setelah ada sumur resapan berkurang menjadi $0,057 \mathrm{~m}^{3} /$ detik, sumur resapan diameter 1,2 dari limpasan sebesar $0,401 \mathrm{~m}^{3} /$ detik dan setelah ada sumur resapan berkurang menjadi $0,0475 \mathrm{~m} / \mathrm{detik}$, dan pada sumur resapan diater $2 \mathrm{~m}$ dari limpasan sebesar $0,377 \mathrm{~m}^{3} /$ detik dan setelah ada sumur resapan berkurang menjadi $0,0571 \mathrm{~m} /$ detik.
\end{abstract}

Kata kunci: volume, banjir, resapan, air tanah .

\section{ABSTRACT}

Changes in land use not only affect the hydrological component, but also have an impact on the environmental sector, which include increasing the frequency of flooding and inundation, decreasing the availability of subsurface water, and drying up community wells. Various attempts have been made in efforts to reduce flooding and maintain sources of subsurface water, for example by applying infiltration well technology in each settlement. Infiltration wells will be able to function to re-enter rainwater falling on the pavement and can reduce flooding and inundation.

This research is conducted with an empirical model that is connecting the amount of runoff that occurs after the availability of recharge wells. The purpose of this research is to get the ability of infiltration wells to reduce the occurrence of flooding in an area. The data used in the analysis are rain data and soil texture data. Based on the analysis results obtained dimensions of $0.8 \mathrm{~m}, 1 \mathrm{~m}$ and $1.2 \mathrm{~m}$ infiltration wells with a depth of $2 \mathrm{~m}$. The depth of ground water level is $1.94 \mathrm{~m}$, the permeability value $(\mathrm{k})$ of land is $0.24 \times 10^{-4} \mathrm{~m} /$ sec. From each of the infiltration well diameters, it can reduce the successive runoff namely; infiltration wells are $0.8 \mathrm{~m}$ in diameter from runoff of $0.479 \mathrm{~m}^{3} / \mathrm{sec}$ and after an infiltration well is reduced to $0.057 \mathrm{~m}^{3} /$ sec, infiltration wells diameter 1.2 from runoff is $0.401 \mathrm{~m}^{3} / \mathrm{sec}$ and after an infiltration well is reduced to $0.0475 \mathrm{~m} / \mathrm{second}$, and in the diater infiltration well $2 \mathrm{~m}$ from runoff of $0.377 \mathrm{~m}^{3} / \mathrm{sec}$ and after the infiltration well is reduced to $0.0571 \mathrm{~m} / \mathrm{sec}$.

Keywords: volume, flooding, infiltration, ground water. 


\section{PENDAHULUAN}

\section{Latar Belakang}

Sumur resapan merupakan sumur atau lubang pada permukaan tanah yang digunakan untuk menampung air hujan agar dapat meresap kedalam tanah. Berbeda dengan sumur air minum, sumur resapan berfungsi untuk memasukkan air ke dalam tanah, sedangkan sumur air minum berfungsi untuk menaikkan air tanah ke permukaan. Dengan demikian konstruksi dan kedalamannya berbeda. Sumur resapan digali dengan kedalaman diatas muka air tanah, sedangkan sumur air minum digali lebih dalam lagi atau dibawah muka air tanah (Fakhrudin, 2010). Sistem resapan buatan ini dapat menampung air hujan melalui atap bangunan atau aliran permukaan yang tidak terserap oleh permukaan tanah, dapat berbentuk sumur, kolam resapan, saluran porous (berpori), dan sejenisnya (Fakhrudin, 2010). Prinsip kerja sumur resapan adalah menyalurkan dan menampung air hujan ke dalam lubang atau sumur agar air dapat memiliki waktu tinggal di permukaan tanah lebih lama, sehingga sedikit demi sedikit air dapat meresap ke dalam tanah (Kusnaedi, 2011).

Genangan dan banjir sering terjadi akibat air hujan tidak dapat meresap ke dalam tanah karena tanah tertutup oleh bangunan-bangunan perumahan. Salah satu alternatif untuk mengatasi permasalahan ini adalah dengan membuat sumur resapan di beberapa titik yang sering terjadi genangan. Selain untuk mengatasi terjadinya banjir dan genangan di permukaan tanah akibat perubahan lahan, pembuatan sumur resapan juga berfungsi sebagai sarana untuk penyediaan air tanah. Daerah perumahan sebenarnya sangat tergantung pada sumber daya air tanah untuk pemenuhan kebutuhan air sehari-harinya.

Seiring dengan meningkatnya pertumbuhan penduduk maka kebutuhan air pun menjadi semakin meningkat. Pembuatan sumur resapan dengan diameter 1 meter dengan kedalaman 10 mater mampu mereduksi limpasan permukaan sebesar 21,82 $\mathrm{m}^{3} /$ detik (Cherish N. A, 2017). Demikian juga dengan penelitian yang dilaksanakan Habib A., (2008) sumur resapan dengan diameter 1,4 kedalam 2 meter dapat mengelimniasi limpasan sebesar 0,029127 m³/detik.

Selain pengaruh diameter dan kedalaman sumur resapan, peranan infiltrasi dan permeabilitas dari tanah memegang peranan penting yang mempengaruhi limpasan yang dapat direduksikan. Setiap wilayah memiliki kapasitas infiltrasi yang berbeda tergantung dari tekstur tanahnya. Type bangunan juga mempengaruhi besar kecilnya limpasan permukaan. Semakin besar bangunan akan menghasilkan limpasan yang besar sebaliknya tipe rumah yang kecil menghasilkan limpasan yang lebih kecil. Untuk 1 unit rumah tipe 60/100 tanpa sumur resapan besarnya limpasan yang dihasilkan adalah $0,647 \times 10^{-3} \mathrm{~m}^{3} / \mathrm{detik}$, setelah ada sumur resapan berkurang menjadi $0,0427 \times 10^{-3} \mathrm{~m}^{3} / \mathrm{detik}$ (Terunajaya,2015)

\section{Rumusan Masalah}

Dari latar belakang yang telah diuraikan, dapat diambil suatu rumusan masalah sebagai berikut:

1. Berapa debit limpasan permukaan sebelum ada sumur resapan

2. Berapa debit yang dapat dikurangi setelah ada sumur resapan

\section{Tujuan dan Manfaat Penelitian}

Penelitan ini bertujuan untuk : mengetahui debit limpasan permukaan sebelum ada sumur resapan dan debit limpasan permukaan setelah ada sumur resapan. Manfaat dari penelitian yaitu sebagai salah satu alternative pengurangan limpasan permukaan dan genangan di kawasan permukiman dan kawasan perkotaan terutama yang menggunakan perkerasan.

\section{METODE PENELITIAN}

\section{Lokasi Penelitian}

Penelitian ini dilaksanakan di perumahan Citra Persada Medas Kecamatan Gunung Sari, Kabupaten Lombok Barat, Provinsi Nusa Tenggara Barat 


\section{Tahapan Penelitian}

\section{Pengumpulan Data}

Data terdiri dari dua macam yaitu data primer dan sekunder. Data primer adalah data yang diperoleh dari hasil pengamatan dan pengukuran secara langsung yang dilakukan di lokasi penelitian sedangkan data sekunder adalah data yang diperoleh dari instansi terkait.

Dalam penelitian ini diperlukan data primer yaitu kedalaman muka air tanah pada lokasi penelitian, kemudian diambil sampel tanahnya untuk dicari nilai permeabilitas (k) di laboratorium. Kemudian untuk data sekunder diperoleh dari instansi terkait. Adapun data sekunder yang dibutuhkan dalam penelitian ini yaitu Data curah hujan stasiun Gunung Sari selama 15 tahun yang diperoleh dari Balai Wilayah Sungai Nusa Tenggara I. Stasiun hujan Gunung Sari dipilih karena terdekat dengan lokasi penelitian.

\section{Alat dan bahan}

a. Pengukuran kedalaman muka air tanah : 1). Sumur air milik warga setempat 2).Meteran, 3). Kertas kosong, 4).Pulpen

b. Uji permeabilitas tanah di laboratorium Metode Constant Head Test : 1). Satu set alat Constant Head Permeameter dengan Sample Chamber, diameter 2.5", tinggi 8", 2).Gelas ukur 500 s/d 1000, 3).Gelas ukur $100 \mathrm{ml}$, 4).Timbangan dengan ketelitian $0.1 \mathrm{gram}, 5)$.Pipa/burette gelas, 6).Stop watch, 7).Porous stone, diameter 2.47”, tebal 0.5”, 8). Jangka sorong

\section{Analisis Data}

Tahapan analisis data adalah sebagai berikut:

1. Pengukuran kedalaman muka air tanah. a). Analisis nilai (k) permeabilitas tanah diLaboratorium, b).Analisis data curah hujan, c). Uji konsistensi data curah hujan dengan menggunakan metode RAPS (Rescaled Adjusted Partial Sums). d).Analisis curah hujan rerata DAS, e).Analisis distribusi frekuensi untuk menentukan jenis agihan/distribusi yang digunakan, f).Uji kecocokan distribusi frekuensi menggunakan metode Chi-Kuadrat dan Smirnov-Kolmogorov, g).Analisis curah hujan rancangan menggunakan metode berdasarkan pada persyaratan jenis distribusinya.

2. Analisis intensitas curah hujan.

3. Analisis debit hidrolika existing saluran drainase.

4. Analisis debit banjir perumahan sebelum ada sumur resapan.

5. Analisis debit air hujan yang masuk ke sumur resapan.

6. Analisis debit banjir perumahan setelah ada sumur resapan.

7. Analisis efesiensi debit banjir akibat sumur resapan.

8. Banjir akibat sumur resapan

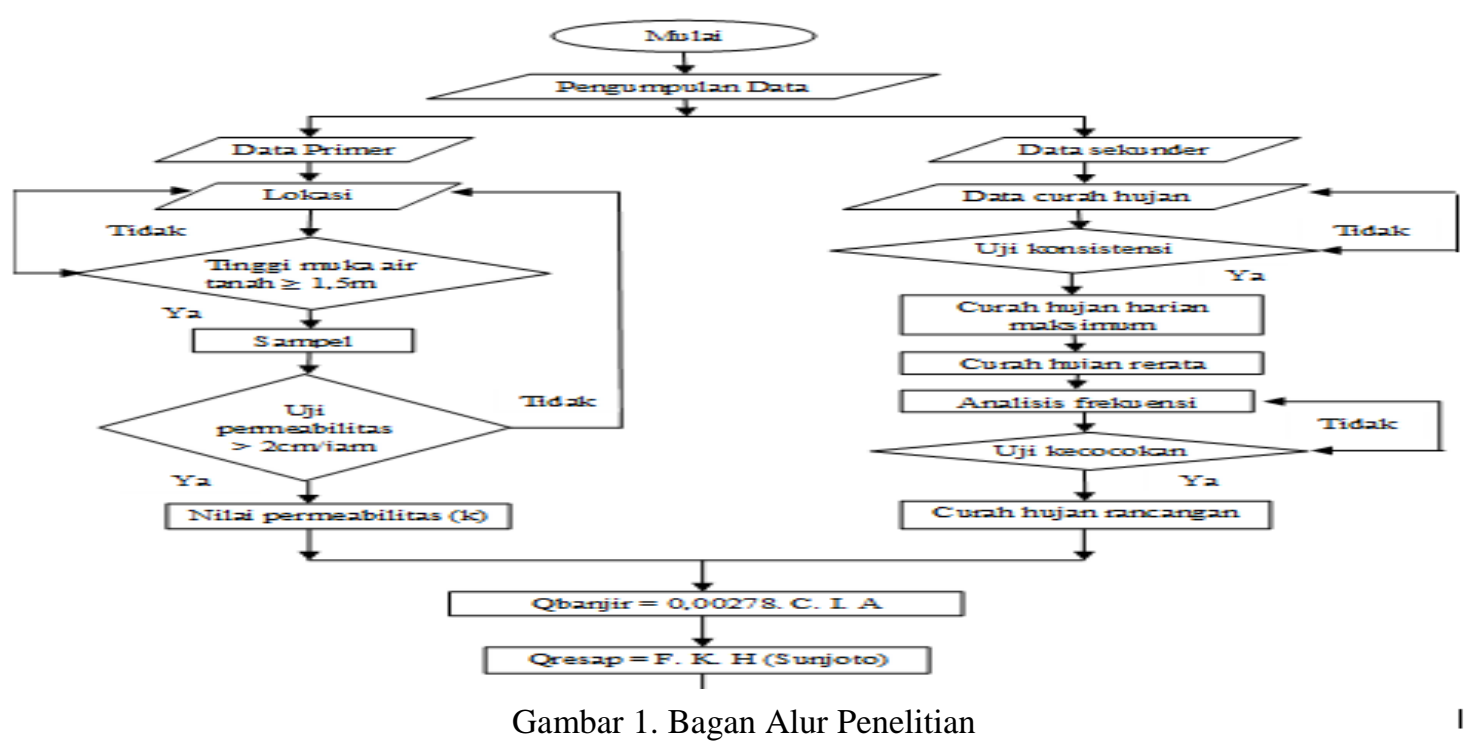




\section{HASIL DAN PEMBAHASAN}

\section{Curah Hujan Rencana}

Curah hujan rencana diperoleh dari analisis hidrologi menggunakan stasiun hujan Gunung Sari dengan panjang data pengamatan selama 15 tahun. Berdasarkan analisis curah hujan rancangan Log Pearson tipe III diperoleh besarnya nilai curah hujan rencana, ditunjukkan seperti pada Tabel 1.

Tabel 1. Nilai Curah Hujan Rancangan

\begin{tabular}{|c|c|}
\hline $\begin{array}{c}\text { PeriodeUlang } \\
\text { (Tahun) }\end{array}$ & $\begin{array}{c}\text { Curah Hujan } \\
(\mathrm{mm})\end{array}$ \\
\hline 2 & 76,474 \\
\hline $\mathbf{5}$ & $\mathbf{1 2 6 , 3 9 1}$ \\
\hline 10 & 159,436 \\
\hline 25 & 201,200 \\
\hline 50 & 232,179 \\
\hline 100 & 262,929 \\
\hline
\end{tabular}

Sumber : Data primer diolah

Berdasarkan Tabel 1, dapat disimpulkan bahwa curah hujan rancangan dengan periode ulang 5 tahun adalah 126,391 mm. Ini menunjukkan curah hujan sebesar 126,391 $\mathrm{mm}$ akan terjadi sekali selama 5 tahun.

\section{Permebilitas Tanah}

Pengukuran permebilitas tanah dilaksanakan pada 3 lokasi. Hal ini dimaksudkan untuk mendapatkan hasil yang lebih baik dan dapat mewakili semua titik. Berdasakan hasil pengujian laboratorium, permebilitas tanah masing-masing lokasi ditunjukkan seperti pada Tabel 2.

Tabel 2. Nilai Permeabilitas Tanah

\begin{tabular}{|c|c|}
\hline Lokasi & Koefisien permeabilitas $(\mathrm{cm} / \mathrm{jam}$ \\
\hline 1 & 8,54 \\
\hline 2 & 8,20 \\
\hline 3 & 8,35 \\
\hline 4 & 8,90 \\
\hline 5 & 9,23 \\
\hline Nilai rata- rata & $\mathbf{8 , 6 4}$ \\
\hline
\end{tabular}

Sumber: Data primer diolah

Berdasarkan Tabel 2. Menunjukan hasil perhitungan nilai rata-rata permeabilitas tanah sebesar 8,64 $\mathrm{cm} / \mathrm{jam}$, yang menunjukkan bahwa genangan air setinggi $8,64 \mathrm{~cm}$ akan surut dalam kurun waktu selama 1 jam dan dapat memenuhi persyaratan yang ada di SNI 03-2453-2002 dengan syarat permeabilitas tanah agak cepat (pasir halus $3,6-36 \mathrm{~cm} / \mathrm{jam}$ ).

\section{Debit Permukaan}

Debit permukaan dihitung pada masing-masing lokasi sesuai dengan tipe rumahnya. Pada lokasi penelitian tipe rumah dibagi menjadi 3 block yaitu block 1, 2 dan 3. Berdasarkan hasil analisis besarnya debit limpasan permukaan ditunjukan seperti pada Tabel 3. 
Tabel 3. Limpasan Permukaan Masing-masing Blok Sebelum Ada Sumur Resapan

\begin{tabular}{|c|c|c|c|c|c|c|}
\hline Blok & $\begin{array}{c}\text { Blok } \\
\text { rumah }\end{array}$ & $\begin{array}{l}\text { Koef. } \\
\text { debit }\end{array}$ & komposit & $\begin{array}{c}\text { Intensitas } \\
\text { hujan } \\
\text { (mm/jam) }\end{array}$ & $\begin{array}{c}\text { Luas } \\
\text { total } \\
\left(\mathbf{m}^{2}\right)\end{array}$ & $\begin{array}{c}\text { Debit banjir } \\
\text { limpasan } \\
\left(\mathrm{m}^{3} / \text { detik }\right)\end{array}$ \\
\hline \multirow{12}{*}{ I } & $\mathbf{A}$ & 0,00278 & 0,631 & 183,003 & 726,8 & 0,0233 \\
\hline & B & 0,00278 & 0,635 & 183,003 & 221,0 & 0,0071 \\
\hline & D & 0,00278 & 0,631 & 183,003 & 727,7 & 0,0233 \\
\hline & $\mathbf{E}$ & 0,00278 & 0,610 & 183,003 & 2623,3 & 0,0813 \\
\hline & $\mathbf{F}$ & 0,00278 & 0,583 & 183,003 & 1405,5 & 0,0417 \\
\hline & G & 0,00278 & 0,630 & 183,003 & 2042,9 & 0,0654 \\
\hline & $\mathbf{H}$ & 0,00278 & 0,601 & 183,003 & 2108,7 & 0,0644 \\
\hline & I & 0,00278 & 0,614 & 183,003 & 2367,2 & 0,0739 \\
\hline & $\mathbf{O}$ & 0,00278 & 0,633 & 183,003 & 645,5 & 0,0208 \\
\hline & $\mathbf{P}$ & 0,00278 & 0,633 & 183,003 & 968,6 & 0,0312 \\
\hline & $\mathbf{Q}$ & 0,00278 & 0,608 & 183,003 & 1487,0 & 0,0460 \\
\hline & Jmlah & & & & & 0,479 \\
\hline \multirow{7}{*}{ II } & $\mathrm{C}$ & 0,00278 & 0,630 & 200,828 & 1859,7 & 0,0654 \\
\hline & $\mathbf{J}$ & 0,00278 & 0,626 & 200,828 & 1758,3 & 0,0615 \\
\hline & $\mathbf{K}$ & 0,00278 & 0,630 & 200,828 & 1859,9 & 0,0654 \\
\hline & $\mathbf{L}$ & 0,00278 & 0,566 & 200,828 & 2007,3 & 0,0634 \\
\hline & $\mathbf{M}$ & 0,00278 & 0,630 & 200,828 & 2061,8 & 0,0725 \\
\hline & $\mathbf{N}$ & 0,00278 & 0,630 & 200,828 & 2061,8 & 0,0725 \\
\hline & Jmlah & & & & & 0,401 \\
\hline \multirow{10}{*}{ III } & $\mathbf{R}$ & 0,00278 & 0,633 & 220,920 & 644,9 & 0,0251 \\
\hline & $\mathbf{S}$ & 0,00278 & 0,633 & 220,920 & 644,9 & 0,0251 \\
\hline & $\mathbf{T}$ & 0,00278 & 0,633 & 220,920 & 644,9 & 0,0251 \\
\hline & $\mathbf{U}$ & 0,00278 & 0,633 & 220,920 & 644,9 & 0,0251 \\
\hline & $\mathbf{V}$ & 0,00278 & 0,635 & 220,920 & 1105,2 & 0,0431 \\
\hline & $\mathbf{W}$ & 0,00278 & 0,636 & 220,920 & 1698,5 & 0,0663 \\
\hline & $\mathbf{X}$ & 0,00278 & 0,590 & 220,920 & 1396,6 & 0,0506 \\
\hline & $\mathbf{Y}$ & 0,00278 & 0,630 & 220,920 & 1656,0 & 0,0641 \\
\hline & $\mathbf{Z}$ & 0,00278 & 0,621 & 220,920 & 1378,8 & 0,0526 \\
\hline & Jmlah & & & & & 0,377 \\
\hline
\end{tabular}

Sumber: Data primer diolah

Berdasarkan Tabel 3 didapatkan debit banjir saluran drainase sebelum ada sumur resapan pada blok I sebesar $0,479 \mathrm{~m}^{3} /$ detik, blok II yaitu $0,401 \mathrm{~m}^{3} /$ detik dan $0,377 \mathrm{~m}^{3} /$ detik pada pada blok III.Sehingga total debit banjir sebelum ada sumur resapan sebesar $1,256 \mathrm{~m}^{3} /$ detik.

\section{Debit Sumur Resapan}

Besarnya debit yang dapat direduksi dengan adanya sumur resapan tergantung dari permeabilitas tanah dan koefisen infiltrasnya selain diameter dan kedalam sumur resapan. Kedalaman sumur resapan dipengaruhi oleh elevasi muka air tanah lokasi penelitian. Berdasarkan hasil analisis, besarnya debit yang bisa dimasukan kedalam sumur resapan yaitu seperti pada tabel berikut : 
Tabel 4. Debit Masuk Sumur Resapan

\begin{tabular}{|c|c|c|c|c|c|c|c|}
\hline $\begin{array}{c}\text { Saluran } \\
\text { drainase } \\
\text { utama }\end{array}$ & $\begin{array}{c}\text { Blok } \\
\text { rumah }\end{array}$ & $\begin{array}{c}\text { Luas } \\
\text { lahan } \\
\left(\mathbf{m}^{2}\right)\end{array}$ & $\begin{array}{c}\text { lahan } \\
\text { sama } \\
\text { (n) }\end{array}$ & C & $\begin{array}{l}\text { Intensitas } \\
(\mathbf{m m} / \mathbf{j a m})\end{array}$ & $\begin{array}{c}\text { Q } \\
\text { sumur per } \\
\text { rumah } \\
\left(\mathbf{m}^{3} / \text { detik }\right)\end{array}$ & $\begin{array}{c}\text { Q } \\
\text { sumur } \\
\text { per } \\
\text { blok } \\
\left(\mathbf{m}^{3} / \text { detik }\right)\end{array}$ \\
\hline \multirow{19}{*}{ I } & $\mathbf{A}$ & 90 & 7 & 0,620 & 183,003 & 0,00284 & 0,0199 \\
\hline & B & 90 & 2 & 0,620 & 183,003 & 0,00284 & 0,0057 \\
\hline & D & 90 & 7 & 0,620 & 183,003 & 0,00284 & 0,0199 \\
\hline & \multirow{3}{*}{$\mathbf{E}$} & 90 & 21 & 0,620 & 183,003 & 0,00284 & \multirow{3}{*}{0,0678} \\
\hline & & 97 & 1 & 0,611 & 183,003 & 0,00302 & \\
\hline & & 205 & 1 & 0,500 & 183,003 & 0,00521 & \\
\hline & \multirow{3}{*}{$\mathbf{F}$} & 90 & 9 & 0,620 & 183,003 & 0,00284 & \multirow{3}{*}{0,0381} \\
\hline & & 237 & 1 & 0,500 & 183,003 & 0,00603 & \\
\hline & & 258 & 1 & 0,500 & 183,003 & 0,00656 & \\
\hline & $\mathbf{G}$ & 90 & 20 & 0,620 & 183,003 & 0,00284 & 0,0568 \\
\hline & \multirow{3}{*}{ H } & 74 & 1 & 0,646 & 183,003 & 0,00243 & \multirow{3}{*}{0,0619} \\
\hline & & 85 & 1 & 0,627 & 183,003 & 0,00271 & \\
\hline & & 90 & 20 & 0,620 & 183,003 & 0,00284 & \\
\hline & \multirow{2}{*}{ I } & 90 & 22 & 0,620 & 183,003 & 0,00284 & \multirow{2}{*}{0,0682} \\
\hline & & 227 & 1 & 0,500 & 183,003 & 0,00577 & \\
\hline & $\mathbf{O}$ & 90 & 6 & 0,620 & 183,003 & 0,00284 & 0,0170 \\
\hline & $\mathbf{P}$ & 90 & 9 & 0,620 & 183,003 & 0,00284 & 0,0255 \\
\hline & 0 & 90 & 12 & 0,620 & 183,003 & 0,00284 & 00405 \\
\hline & $\mathbf{Q}$ & 254 & 1 & 0,500 & 183,003 & 0,00646 & 0,0405 \\
\hline & Jumlah & & & & & & 0,421 \\
\hline \multirow{9}{*}{ II } & $\mathbf{C}$ & 90 & 18 & 0,620 & 200,828 & 0,00312 & 0,056 \\
\hline & $\mathbf{J}$ & 90 & 18 & 0,620 & 200,828 & 0,00312 & 0,056 \\
\hline & $\mathbf{K}$ & 90 & 18 & 0,620 & 200,828 & 0,00312 & 0,056 \\
\hline & \multirow{4}{*}{$\mathbf{L}$} & 90 & 16 & 0,620 & 200,828 & 0,00312 & \multirow{4}{*}{0,061} \\
\hline & & 95 & 1 & 0,614 & 200,828 & 0,00325 & \\
\hline & & 101 & 1 & 0,607 & 200,828 & 0,00342 & \\
\hline & & 122 & 1 & 0,589 & 200,828 & 0,00401 & \\
\hline & $\mathbf{M}$ & 90 & 20 & 0,620 & 200,828 & 0,00312 & 0,062 \\
\hline & $\mathbf{N}$ & 90 & 20 & 0,620 & 200,828 & 0,00312 & 0,062 \\
\hline & Jumlah & & & & & & 0,320 \\
\hline \multirow{14}{*}{ III } & $\mathrm{R}$ & 90 & 6 & 0,620 & 220,920 & 0,00343 & 0,0206 \\
\hline & $S$ & 90 & 6 & 0,620 & 220,920 & 0,00343 & 0,0206 \\
\hline & $\mathrm{T}$ & 90 & 6 & 0,620 & 220,920 & 0,00343 & 0,0206 \\
\hline & $\mathrm{U}$ & 90 & 6 & 0,620 & 220,920 & 0,00343 & 0,0206 \\
\hline & $\mathrm{V}$ & 90 & 10 & 0,620 & 220,920 & 0,00343 & 0,0343 \\
\hline & $\mathrm{W}$ & 90 & 17 & 0,620 & 220,920 & 0,00343 & 0,0583 \\
\hline & \multirow{2}{*}{$\mathrm{X}$} & 90 & 12 & 0,620 & 220,920 & 0,00343 & \multirow{2}{*}{0,0457} \\
\hline & & 129 & 1 & 0,584 & 220,920 & 0,00462 & \\
\hline & $\mathrm{Y}$ & 90 & 16 & 0,620 & 220,920 & 0,00343 & 0,0548 \\
\hline & \multirow{5}{*}{ Z } & 90 & 8 & 0,620 & 220,920 & 0,00343 & \multirow{5}{*}{0,0445} \\
\hline & & 95 & 1 & 0,614 & 220,920 & 0,00358 & \\
\hline & & 110 & 1 & 0,598 & 220,920 & 0,00404 & \\
\hline & & 122 & 1 & 0,589 & 220,920 & 0,00441 & \\
\hline & & 144 & 1 & 0,575 & 220,920 & 0,00509 & \\
\hline & Jumlah & & & & & & 0,353 \\
\hline & Total & & & & & & 1,095 \\
\hline
\end{tabular}

Sumber : Data primer diolah 
Berdasarkan Tabel 4 didapatkan debit masuk sumur resapan pada blok I sebesar 0,421 m/detik, 0,320 $\mathrm{m}^{3} /$ detik pada blok II dan $0,353 \mathrm{~m}^{3} /$ detik dan blok III.Sehingga total debit sumur resapan sebesar 1,095 $\mathrm{m}^{3} /$ detik.

\section{Reduksi Limpasan Permukaan Setelah Ada Sumur Resapan}

Besarnya reduksi limpasan permukaan dengan sumur resapan menunjukan pengurangan yang signifikan, sehingga dapat mengurangi terjadinya banjir dikawasan perumahan. Gambar berikut menunjukkan reduksi limpasan permukaan pada masing-masing blok.

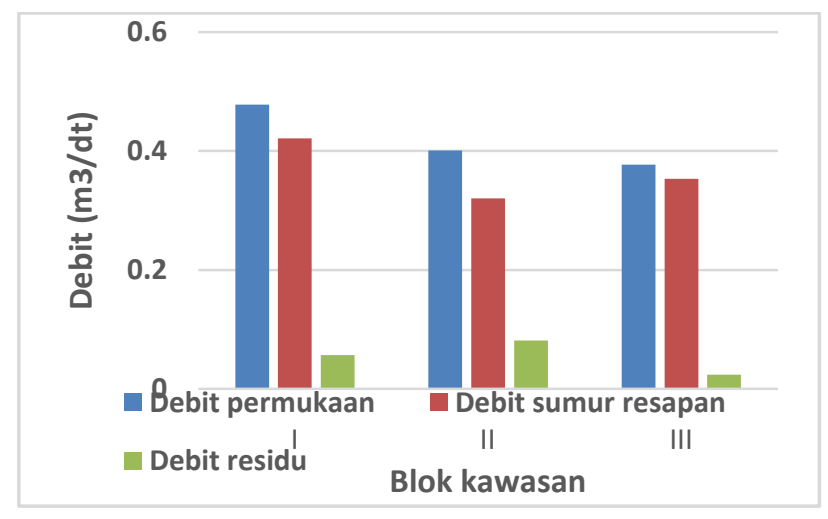

Gambar 2. Grafik reduksi limpasan permukaan setelah ada sumur resapan

Berdasarkan Gambar 2. menunjukkan bahwa debit limpasan permukaan akan dapat tereduksi sangat signifikan. Rata-rata debit yang tersisa menjadi limpasan permukaan setelah adanya sumur resapan yaitu berkisar antara $10-20 \%$.

\section{SIMPULAN DAN SARAN}

\section{Simpulan}

Dari hasil penilitian dapat disimpulkan sebagai berikut :

1. Berdasarkan data yang telahdianalisis didapat debit banjir sebelum ada sumur resapan pada Kawasan blokIsebesar $0,479 \mathrm{~m}^{3} /$ detik, blokII sebesar $0,401 \mathrm{~m}^{3} /$ detik, danblokIII sebesar $0,377 \mathrm{~m}^{3} /$ detik.

2. Debit banjir residu setelah ada sumur resapan yaitu masing blok Isebesar $0,057 \mathrm{~m}^{3} /$ detik, blokII sebesar $0,0475 \mathrm{~m}^{3} /$ detik, danblok III sebesar $0,0571 \mathrm{~m}^{3} /$ detik.

\section{Saran}

Dari penelitian yang telah dilakukan ada beberapa hal yang dapat dijadikan sebagai masukan atau saran untuk pengembangan selanjutnya, antara lain :

1. Untuk penerapan sumur resapan di masing-masing wilayah sangat penting mempertimbangkan kondisi tekstur tanah dan kapasitas infiltrasi tanah, sehingga besarnya limpasan permukaan akan berbeda-beda.

2. Diperlukan kesadaran dan partisipasi masyarakat untuk membangun sumur resapan dimasing-masing kawasan karena besarnya limpasan permukaan yang dapat dikurangi

\section{DAFTAR PUSTAKA}

Cherish A.N., 2017. Efektivitas Sumur Infiltrasi Untuk Mengurangi Kelebihan Permukaan Limpasan: Institut Teknologi Bandung.

Fahkrudin. 2010. Sumur Resapan Untuk Pemukiman Perkotaan dan Pedesaan, Penerbar Swadaya. Jakarta.

Habib A., 2008. Alternatif Sumur Resapan Untuk Pengendali Limpasan Air Hujan. Universitas Islam Malang. Malang

Kusnaedi.2011. Sumur Resapan Untuk Pemukiman Perkotaan dan Pedesaan, Penebar Swadaya. Jakarta.

Terunajaya. 2015. Pengaruh Infiltrasi dan Permeabilitas Terhadap Sumur Resapan. Universitas Sumatra Utara. Medan 